\title{
The Glycans of Stem Cells
}

\author{
Pascal M. Lanctot ${ }^{1,2}$, Fred H. Gage ${ }^{2}$, and Ajit P. Varki ${ }^{1}$ \\ 1 Glycobiology Research and Training Center, Departments of Medicine and Cellular \& Molecular Medicine, \\ University of California at San Diego, La Jolla, CA 92093, USA \\ 2 Laboratory of Genetics, Salk Institute for Biological Studies, 10010 North Torrey Pines Road, La Jolla, \\ California 92037, USA
}

\section{Summary}

Glycans cover all cellular surfaces and, not surprisingly, are involved in many facets of stem cell biology and technology. For instance, coaxing stem cells to either proliferate or differentiate into the specific cell types needed for transplantation requires intricate glycan-dependent modulation of signalling molecules such as FGF-2, Wnt and Notch. Moreover, due to their prominent cell-surface localization and lineage-specific signatures, glycan epitopes such as the stage-specific embryonic antigens (Lewis X/SSEA-1, SSEA3-4) and tumor-rejection antigens (TRA1-60,1-81) are ideally suited for identifying and isolating specific cell types from heterogeneous populations. Finally, the non-human sialic acid Neu5Gc has been detected on the surface of human embryonic stem cells due to metabolic incorporation from animal products used for their culture. Transplantation of Neu5Gccontaminated cells poses immunological risks due to the presence, in humans, of circulating antibodies recognizing this glycan epitope.

\section{Introduction}

In addition to nucleic acids, proteins and lipids, oligosaccharides and polysaccharides (hereafter called glycans) are the fourth major class of cellular macromolecules. Glycans are often attached to proteins and lipids and form a dense glycocalyx on the surface of all cells, including embryonic and pluripotent stem cells. Research in the field of glycobiology has identified diverse and complex biological roles for these glycans [1]. As the most prominent aspect of a stem cell that faces neighbours and molecules of the extracellular milieu, components of the glycocalyx are optimally positioned to help the stem cell communicate with its environment, and interact with its niche.

Although glycans are critically involved in the intracellular maturation (folding and transport) of many glycoproteins [2] essential for stem cell viability, these aspects will not be covered here. Rather, we consider examples of how extracellular glycans can be exploited to modulate the growth and differentiation of stem cells in vitro, as well as to isolate and purify specific stem cell lineages. Furthermore, due to their potentially antigenic nature, stem cell glycans must be scrutinized to insure that grafts are free from any contaminants that could lead to their rejection.

Corresponding author: Ajit Varki: E-mail: a1 varki@ucsd.edu.

Publisher's Disclaimer: This is a PDF file of an unedited manuscript that has been accepted for publication. As a service to our customers we are providing this early version of the manuscript. The manuscript will undergo copyediting, typesetting, and review of the resulting proof before it is published in its final citable form. Please note that during the production process errors may be discovered which could affect the content, and all legal disclaimers that apply to the journal pertain. 


\section{Glycans can help identify and isolate specific stem cell lineages}

Glycans are the first cellular component encountered by approaching cells, pathogens, antibodies and other molecules. Hence, it is not surprising that hybridoma screens frequently generate antibodies directed against cell-surface glycans. In addition, different cell types express different glycan signatures, a property which has also been utilized to identify cancer cells. These two fundamental characteristics of glycans (antigenicity and lineage specific signatures) make them ideal for the identification and purification of stem cells.

The ABO blood group system is one clinically relevant instance where endogenous antibodies to specific glycan structures in one person can cause rejection of blood transfusions from another, a fate that would also occur to mismatched transplanted stem cells. Although the cause of rejection was unknown when the ABO system was elucidated about a century ago, subsequent work led to the identification of the glycosyltransferase alleles capable of making the $\mathrm{A}$ and $\mathrm{B}$ antigens, and the generation of corresponding anti-A and anti-B antibodies [3].

A prominent member of the Lewis blood group-antigen family is Lewis $\mathrm{X}$, which can be found on glycoproteins, glycolipids and proteoglycans. Its antigenic nature is highlighted by the fact that over 20 independent groups have generated monoclonal antibodies against this trisaccharide structure. They include, among many others, anti-SSEA-1 [4], MMA [5], TEC-1 [6] and FORSE-1 [7]. Most of the antibodies were generated through the study of developmental processes or cancer, in which situations Lewis $\mathrm{X}$ is known to be widely expressed [8].

We also recently performed a hybridoma screen to identify novel and more specific markers for neural stem cells. Initial selection of clones was based on immunoreactivity in the subventricular zone and subgranular zone of the hippocampus, the two brain regions known to generate new neurons throughout life. Further characterization of our clone revealed the generation of another member in the vast repertoire of Lewis X antibodies (PM Lanctot et al., Abstract 238 in Glycobiology 16(11):1149, Society for Glycobiology, Los Angeles, November 2006). Capela et al. had previously reported that sorting SVZ cells based on expression of Lewis $\mathrm{X}$ was a good strategy to enrich a restricted but highly proliferative neural stem cell population (Figure 1) [9]. Similar properties are observed with cells sorted on the basis of the 473HD epitope [10], probably due to the fact that Lewis X and 473HD epitopes can be carried by RPTP $\alpha /$ phosphacan.

The glycolipids SSEA-3 and SSEA-4 are amongst the most commonly used markers to identify embryonic stem cells [8]. Their structure consists of 5-6 monosaccharides attached to a ceramide lipid tail, forming the globoseries glycosphingolipids GL-5 and GL-7 (Figure 2). Their presence in the plasma membrane decreases rapidly upon differentiation, making them useful markers of pluripotency. On the other hand, SSEA-3 and -4 were recently shown not to be essential for maintenance of human embryonic stem cells (hESC) pluripotency as their depletion using glycolipid biosynthesis inhibitors had no significant effect on the cell's ability to remain undifferentiated [11].

Sialic acids are a family of monosaccharides typically found at the outer most ends of glycans (Figure 2)[12]. For this reason, many cell type-specific antibodies recognize sialic acid on various macromolecules. Among these, the heavily glycosylated sialomucin molecule CD34 is the most clinically relevant, due to its extensive use in the separation of bone marrow cells for transplantation. The tumor rejection antigens (TRA) are another family of widely used markers of ESC. Although the exact structural determinants of their epitopes are unknown, TRA-1-60 and TRA-1-81 have been shown to recognize a keratan sulfated proteoglycan (KSPG) in neuraminidase-sensitive and insensitive fashion, respectively [13]. The search for the carrier of the TRA family antigens in embryonal carcinoma cells has led to the identification 
of podocalyxin, a heavily sialylated membrane protein structurally similar to CD34 [14]. Another CD marker used to identify and purify neural stem cells is CD133. This five transmembrane domain cell-surface glycoprotein, also called prominin-1, has been effectively used to isolate clonogenic multipotent neural stem cells from human fetal brain tissue [15].

PSA-NCAM (polysialylated neural cell adhesion molecule) is prominent cell-surface glycan marker and a developmentally regulated glycoprotein with multiple immunoglobulin domains. One unusual feature of PSA-NCAM is its modification with a unique and abundant linear homopolymer composed of $\alpha 2-8$-linked sialic acids (Figure 2). Polysialic acid has been suggested to act as a repulsive signal against interactions of immature neurons/axons. PSANCAM's involvement in many aspects of neurogenesis and plasticity such as cell migration, axonal growth, fasciculation and synaptogenesis are well documented [16]. Antibodies have been generated against both the NCAM and PSA portions of the molecule and the PSA-specific antibody can be used to identify and isolate stem cells that have opted for the neuronal lineage (Figure 1). Contribution of the sialic acid moiety of PSA-NCAM was recently highlighted by genetic deletion of the two sialyltransferases (ST8Sia-II and ST8Sia-IV) capable of synthesizing PSA in the brain. Interestingly, this double knockout mouse displayed a more severe neurodevelopmental "gain-of-function" phenotype than deletion of NCAM (and thus PSA) [17], most likely due to untimely homotypic binding of non-PSA bearing NCAM.

\section{Cell-surface glycans can modulate many signalling pathways}

Mitogens and morphogens must traverse the dense sugar coat surrounding stem cells to elicit intracellular responses. Components of this glycocalyx are therefore ideally situated to modulate a plethora of signalling processes. In the limited space available, we will briefly discuss three specific pathways that offer striking examples of how stem cell signaling pathways critically depend on posttranslational modification by attached glycans (Notch) or how other glycans function as co-receptors for growth factor binding (FGF-2, Wnt).

FGF-2 is a widely used mitogen for culturing many stem cell types. Indeed, this growth factor is often a key player in regulating self-renewal and proliferation of stem cells. Since the first fibroblast growth factor was isolated and characterized over 30 years ago [18], the FGF family has grown not only in number but was also shown to be involved in multiple processes such as proliferation, differentiation, cell migration, tissue repair, wound healing and tumor angiogenesis. It is now understood that, in order to signal effectively, FGFs must bind to both high-affinity FGF receptors and lower-affinity heparan sulfate proteoglycans (HSPGs)[19]. Proteoglycans are a large family of secreted and cell-surface molecules composed of a core protein such as aggregan, glypican, perlecan or syndecan to which are attached long chains of repeating sulfated disaccharide units chains such as heparan sulfate (Figure 2). Another molecule shown to modulate the mitogenic aspects of FGF-2 signalling in neural stem cells is Cystatin C, a secreted polypeptide identified as a cysteine proteinase inhibitor [20].

Interestingly, the autocrine/paracrine effect of $\mathrm{CCg}$ in rat was critically dependant on its single $\mathrm{N}$-glycosylation site but not on its protease inhibitor domain [21].

The Wnt family of growth/differentiation factors has important developmental roles from embryonic through adult stem cells and genetic mutations increasing their signalling have been observed in several cancers. Like the FGF family, Wnts must bind heparan sulfate proteoglycans for optimal signalling. It has recently been shown that Wnt-3 is critical for adult rodent hippocampal neurogenesis [22], suggesting an important role for proteoglycans in the Wnt-dependant formation on new neurons. HSPGs are not the only glycans to interact with Wnts. Indeed, Capela et al. have shown a direct interaction between Lewis X and Wnt-1 through co-immunoprecipitation experiments [23]. Based on these results and colocalization studies placing Lewis $\mathrm{X}$ in close anatomical proximity to FGF-2, FGF-8 and Wnt, they propose a 
mechanism whereby LeX could bind these and other molecules, helping to delineate specific regions of the developing brain.

Complex interplay involving mito/morphogen signaling undoubtedly plays critical roles in stem cell fate determination and Notch is a key regulator in many cell types. Notch is an essential developmental glycoprotein with a large extracellular domain made up of 29-36 EGF repeats, which can harbor many $\mathrm{N}$ - and O-linked glycans. Two novel glycan modifications are critically involved in regulating Notch signaling. Initially, a protein O-fucosyltransferase enzyme adds fucose directly to the hydroxyl group of serine/threonine residues in certain Notch EGF repeats [24]. The fucosylated receptor thereby becomes a substrate for Fringe, an Nacetylglucosaminyltransferase, which adds a GlcNAc residue [25]. The action of these two glycosyltransferases, which is necessary for further elongation by two other monosaccharides, has been shown to differentially modulate Notch binding to its ligands delta and serrate [26], thus highlighting how glycans can participate in cell fate determination.

\section{Non-human glycans can contaminate embryonic stem cells}

Due to the antigenic nature of glycans found on clinically relevant recombinant glycoproteins such as cytokines and antibodies, the pharmaceutical and biotech industries are going to great lengths insuring that the glycan portion of their therapeutic glycoproteins can safely cohabit with the human immune system. Indeed, the humanization of glycosylation pathways in yeast [27] and genetic modification of recombinant protein-producing cells such as CHOs has attracted much attention in academic and commercial research laboratories.

Even though embryonic stem cells currently being developed are of human origin, a potential problem is the use of animal by-products such as serum and feeder layers to derive and subsequently culture these cells. Even the so-called "serum-free" media contain components of animal origin. Thus, it is important to address the introduction of potential contaminants into stem cell lines proposed for therapeutic applications in humans. While such contaminants may have no known consequence in the culture dish, they could cause significant risks when introduced into a human patient.

Humans are incapable of synthesizing the common mammalian sialic acid Neu5Gc, due to an Alu transposon-mediated inactivation of the $C M A H$ gene $[28,29]$. Despite this, it was recently shown that human embryonic stem cell lines express cell surface Neu5Gc, apparently originating both from the murine feeder layers and the animal-derived components of the culture media [30]. The significant levels of Neu5Gc found on the surface of hESC evidently originate from a "Trojan Horse" pathway involving endocytosis of extracellular glycoconjugates, delivery to the lysosome, release of Neu5Gc by a lysosomal sialidase, active transport to the cytoplasm through the lysosomal sialic acid transporter, activation by CMP and addition to nascent glycoprotein and glycolipids in the secretory pathway (Figure 3) [31]. It is also possible that amphipathic molecules carrying Neu5Gc (such as glycolipids and GPIanchored proteins) might be directly transferred into the hESC plasma membranes (Figure 3). At the present time, the significance of this contamination for cell therapies is uncertain.

However, regardless of the mechanisms resulting in surface display of Neu5Gc, it would seem undesirable to transplant such Neu5Gc-expressing stem cells into humans. The main reason is that anti-Neu5Gc antibodies are found in the blood of all humans [32], with some individuals even displaying very high titers of antibodies against several different Neu5Gc-containing glycoconjugates (V Padler-Karavani et al., Abstract 314 in Glycobiology 16(11):1164, Society for Glycobiology, Los Angeles, November 2006). Thus different normal human sera deposited varying amounts of antibody and complement onto these Neu5Gc-contaminated cells [30]. Even though cell lysis was not very much above the high background levels in these in vitro assays, such complement and antibody deposition would mark the cells for attack by the innate immune system in vivo. 
Current protocols for the generation and large-scale propagation of human embryonic stem cells (HESC) require animal products such as feeder layers and serum, which evidently contribute the contaminant Neu5Gc to HESC lines grown in their presence. We, and many others, are currently developing various approaches to address potential HESC contaminants. Although several alternative "non-contaminating" approaches are being developed [33-36], they have not yet achieved the efficiency of mouse embryonic fibroblasts. For example human feeders are difficult to obtain in large quantities and feeder-free (matrigel or laminin) and/or animal serum-free conditions can cause premature differentiation and/or karyotypic instability. Unfortunately, matrigel also contains Neu5Gc.

We and others have also shown that the Neu5Gc content of human embryonic and mesenchymal stem cells is substantially reversible by growing them with human serum and that stem cell differentiation decreases Neu5Gc content $[30,37]$. This could also explain why Nasonkin et al observed very low concentrations of Neu5Gc in HESC differentiated to neural precursors [38]. Another explanation is that cells of neural origin have mechanisms in place to prevent Neu5Gc from being expressed (PM Lanctot et al., unpublished). Regardless, it may be difficult to apply such approaches to the scale-ups needed for obtaining large amounts of differentiated cells for transplantation.

Because most humans tested thus far have significant amounts of anti-Neu5Gc antibodies in their sera, common sense suggests that therapeutic transplantation of Neu5Gc-expressing living cells into an immunocompetent human is undesirable. Whether or not negative effects of this non-human sialic acid are observed in vitro [39], the equation remains fairly simple: the combination of Neu5Gc on grafted hESC and Neu5Gc antibodies in human recipient sera is a bad one. Thus, we and others are currently exploring the use of several Neu5Gc-free alternatives [34,40], including growth of HESC on MEFs derived from CMAH null mice unable to make Neu5Gc (unpublished observations).

Many other known high-titer natural antibodies found in normal human blood display antiglycan specificity. These include the anti-blood group A and B antibodies [3] and anti-T (Thomsen-Friedenreich) antibody [41]. Another high titer antibody present in human blood is the anti- $\alpha$-Gal antibody, which binds a common glycan moiety (galactose- $\alpha 1-3$-galactose) found in mammals other than Old World primates. This $\alpha$-Gal antibody was shown to be an abundant component of human blood, representing as much as $1 \%$ of circulating $\operatorname{IgG}[42,43]$. A cell expressing $\alpha$-Gal on its surface attracts immediate attention from the complement pathway and other aspects of the innate immune system upon transplantation into an immunecompetent human host. Hewitt et al. [44] took advantage of this situation when they created genetically modified HESC expressing $\alpha$-Gal under the control of the hTERT promoter, i.e. only in the undifferentiated state. Because HESC can form teratomas, an unwanted side-effect from any residual undifferentiated HESC in cell-based therapy, any $\alpha$-Gal expressing cell would be eliminated in immune competent hosts. However, any inadvertent loss of genetic control of this expression could prove detrimental. Interestingly, it was recently shown that the $\alpha$-Gal epitope possesses adjuvant-like properties, thereby increasing the generation of antibodies against its underlying protein structure, in this case BSA [45]. A similar antibody response against underlying HESC proteins carrying Neu5Gc could favour rejection not only of transplanted cells but could potentially cause auto-immune reactions against the patients own cells.

\section{Conclusion}

Dynamic analysis of the stem cell's glycome in the undifferentiated, differentiating and terminally differentiated state will allow investigators to harness the full power of glycans as stem cell markers and signalling effectors. These important questions have recently been addressed by several groups. For example, although the nucleus is likely bustling with genetic 
and epigenetic activity when a stem cell commits to differentiation, Nash et al. found that downregulation of a GalNAc epitope on mouse embryonic stem cells could be one of the first observable cell-surface phenomenon [46]. Furthermore, lectin-based profiling of glycans signatures have been performed on undifferentiated SSEA-4+ hESC [47] as well as differentiated day 12 embryoid bodies [48]. More detailed studies using similar approaches will help characterize the glycome of many stem cell states and lineages.

Although the expression pattern of many stem cell glycans has been well characterized, a better understanding of their functional roles is much needed. It is likely that the highly conserved glycan epitopes will have important roles in the self-renewal and differentiation of stem cells in vivo, either through niche interactions or signalling modulation. One thing is for certain, that glycans will be extensively utilized and critically contribute to the use of stem cells for future therapeutic transplantation. At the same time, they can pose immunological barriers that must be carefully considered.

\section{Acknowledgments}

The authors thank Pascal Gagneux, Carol Marchetto and Alysson Muotri for helpful discussions and critical reading of the manuscript, and Dr. Gagneux for help with the figures. Funding was provided by NIH Grant R01GM32373 (A.V.)

\section{References}

1. Varki, A.; Cummings, R.; Esko, J.; Freeze, H.; Hart, G.; Marth, J. Essentials of Glycobiology. Vol. 1. Cold Spring Harbor Laboratory Press; New York: 1999.

2. Trombetta ES, Parodi AJ. Quality control and protein folding in the secretory pathway. Annu Rev Cell Dev Biol 2003;19:649-676. [PubMed: 14570585]

3. Yamamoto F, Clausen H, White T, Marken J, Hakomori S. Molecular genetic basis of the histo-blood group ABO system. Nature 1990;345:229-233. [PubMed: 2333095]

4. Solter D, Knowles BB. Monoclonal antibody defining a stage-specific mouse embryonic antigen (SSEA-1). Proc Natl Acad Sci U S A 1978;75:5565-5569. [PubMed: 281705]

5. Hanjan SN, Kearney JF, Cooper MD. A monoclonal antibody (MMA) that identifies a differentiation antigen on human myelomonocytic cells. Clin Immunol Immunopathol 1982;23:172-188. [PubMed: 6179666]

6. Draber P, Pokorna Z. Differentiation antigens of mouse teratocarcinoma stem cells defined by monoclonal antibodies. Cell Differ 1984;15:109-113. [PubMed: 6535637]

7. Allendoerfer KL, Magnani JL, Patterson PH. FORSE-1, an antibody that labels regionally restricted subpopulations of progenitor cells in the embryonic central nervous system, recognizes the $\mathrm{Le}(\mathrm{x})$ carbohydrate on a proteoglycan and two glycolipid antigens. Mol Cell Neurosci 1995;6:381-395. [PubMed: 8846006]

8. Muramatsu T, Muramatsu H. Carbohydrate antigens expressed on stem cells and early embryonic cells. Glycoconj J 2004;21:41-45. [PubMed: 15467397]

9. Capela A, Temple S. LeX/ssea-1 is expressed by adult mouse CNS stem cells, identifying them as nonependymal. Neuron 2002;35:865-875. [PubMed: 12372282]

10. von Holst A, Sirko S, Faissner A. The unique 473HD-Chondroitinsulfate epitope is expressed by radial glia and involved in neural precursor cell proliferation. J Neurosci 2006;26:4082-4094. [PubMed: 16611825]

11. Brimble SN, Sherrer ES, Uhl EW, Wang E, Kelly S, Merrill AH Jr, Robins AJ, Schulz TC. The Cell Surface Glycosphingolipids SSEA-3 and SSEA-4 are not Essential for Human ES Cell Pluripotency. Stem Cells. 2006

12. Badcock G, Pigott C, Goepel J, Andrews PW. The human embryonal carcinoma marker antigen TRA-1-60 is a sialylated keratan sulfate proteoglycan. Cancer Res 1999;59:4715-4719. [PubMed: 10493530] 
13. Schopperle WM, Dewolf WC. The TRA-1-60 and TRA-1-81 Human Pluripotent Stem Cell Markers Are Expressed on Podocalyxin in Embryonal Carcinoma. Stem Cells 2007;25:723-730. [PubMed: 17124010]

14. Uchida N, Buck DW, He D, Reitsma MJ, Masek M, Phan TV, Tsukamoto AS, Gage FH, Weissman IL. Direct isolation of human central nervous system stem cells. Proc Natl Acad Sci U S A 2000;97:14720-14725. [PubMed: 11121071]

15. Bonfanti L. PSA-NCAM in mammalian structural plasticity and neurogenesis. Prog Neurobiol 2006;80:129-164. [PubMed: 17029752]

16. Weinhold B, Seidenfaden R, Rockle I, Muhlenhoff M, Schertzinger F, Conzelmann S, Marth JD, Gerardy-Schahn R, Hildebrandt H. Genetic ablation of polysialic acid causes severe neurodevelopmental defects rescued by deletion of the neural cell adhesion molecule. J Biol Chem 2005;280:42971-42977. [PubMed: 16267048]

17. Gospodarowicz D. Localisation of a fibroblast growth factor and its effect alone and with hydrocortisone on 3T3 cell growth. Nature 1974;249:123-127. [PubMed: 4364816]

18. Yayon A, Klagsbrun M, Esko JD, Leder P, Ornitz DM. Cell surface, heparin-like molecules are required for binding of basic fibroblast growth factor to its high affinity receptor. Cell 1991;64:841848. [PubMed: 1847668]

19. Barrett AJ, Davies ME, Grubb A. The place of human gamma-trace (cystatin C) amongst the cysteine proteinase inhibitors. Biochem Biophys Res Commun 1984;120:631-636. [PubMed: 6203523]

20. Taupin P, Ray J, Fischer WH, Suhr ST, Hakansson K, Grubb A, Gage FH. FGF-2-responsive neural stem cell proliferation requires CCg, a novel autocrine/paracrine cofactor. Neuron 2000;28:385-397. [PubMed: 11144350]

21. Lie DC, Colamarino SA, Song HJ, Desire L, Mira H, Consiglio A, Lein ES, Jessberger S, Lansford $\mathrm{H}$, Dearie AR, et al. Wnt signalling regulates adult hippocampal neurogenesis. Nature 2005;437:1370-1375. [PubMed: 16251967]

$22 *$. Capela A, Temple S. LeX is expressed by principle progenitor cells in the embryonic nervous system, is secreted into their environment and binds Wnt-1. Dev Biol 2006;291:300-313. [PubMed: 16458284]The authors, who had previously established Lewis $\mathrm{X}$ as a neural stem cell marker, now show a potential functional role for this glycan through its ability to coimmunoprecipitate Wnt-1. They also show, in cortical sections, that Lewis $\mathrm{X}$ is in close anatomical proximity to FGF-8 and Wnt-1 by immunostaining. This paves the way for the identification of biological functions for this common antigenic trisaccharide, in addition to its well known uses to identify and purify neural and hematopoeitic stem cells (see figure 2).

23. Moloney DJ, Shair LH, Lu FM, Xia J, Locke R, Matta KL, Haltiwanger RS. Mammalian Notch1 is modified with two unusual forms of O-linked glycosylation found on epidermal growth factor-like modules. J Biol Chem 2000;275:9604-9611. [PubMed: 10734111]

24. Moloney DJ, Panin VM, Johnston SH, Chen J, Shao L, Wilson R, Wang Y, Stanley P, Irvine KD, Haltiwanger RS, et al. Fringe is a glycosyltransferase that modifies Notch. Nature 2000;406:369375. [PubMed: 10935626]

25. Yang LT, Nichols JT, Yao C, Manilay JO, Robey EA, Weinmaster G. Fringe glycosyltransferases differentially modulate Notch1 proteolysis induced by Delta1 and Jagged1. Mol Biol Cell 2005;16:927-942. [PubMed: 15574878]

26. Hamilton SR, Davidson RC, Sethuraman N, Nett JH, Jiang Y, Rios S, Bobrowicz P, Stadheim TA, $\mathrm{Li} \mathrm{H}$, Choi BK, et al. Humanization of yeast to produce complex terminally sialylated glycoproteins. Science 2006;313:1441-1443. [PubMed: 16960007]

27. Chou HH, Takematsu H, Diaz S, Iber J, Nickerson E, Wright KL, Muchmore EA, Nelson DL, Warren ST, Varki A. A mutation in human CMP-sialic acid hydroxylase occurred after the Homo-Pan divergence. Proc Natl Acad Sci U S A 1998;95:11751-11756. [PubMed: 9751737]

28. Hayakawa T, Satta Y, Gagneux P, Varki A, Takahata N. Alu-mediated inactivation of the human CMP- N-acetylneuraminic acid hydroxylase gene. Proc Natl Acad Sci U S A 2001;98:11399-11404. [PubMed: 11562455]

29**. Martin MJ, Muotri A, Gage F, Varki A. Human embryonic stem cells express an immunogenic nonhuman sialic acid. Nat Med 2005;11:228-232. [PubMed: 15685172]In this study, the authors demonstrate that "NIH approved" human embryonic stem cell line H1 expresses high levels of the 
non-human sialic acid Neu5Gc in its cell-surface glycocalyx, resulting in deposition of IgG and complement upon exposure to human sera. The sources of contamination are the mouse embryonic fibroblast feeder layers and the serum replacement component of culture medium. They also demonstrate that culturing the hESC in human serum rather than animal serum can significantly decrease the amount of Neu5Gc on the cell surface.

30**. Bardor M, Nguyen DH, Diaz S, Varki A. Mechanism of uptake and incorporation of the non-human sialic acid N-glycolylneuraminic acid into human cells. J Biol Chem 2005;280:4228-4237. [PubMed: 15557321]This paper shows how non-human sialic acid Neu5Gc can be integrated into the glycocalyx of a human cell line grown in its presence. Briefly, the authors show how Neu5Gc containing molecules are taken up into the lysosomal compartment by macropinocytosis, where free Neu5Gc is released, transported to the cytoplasm, activated by CMP in the nucleus, transported again into the Golgi apparatus, and finally transferred onto a nascent glycoprotein (see Figure 3 of this review). We propose a similar mechanism to explain the contamination of HESC by Neu5Gc.

31. Nguyen DH, Tangvoranuntakul P, Varki A. Effects of natural human antibodies against a nonhuman sialic acid that metabolically incorporates into activated and malignant immune cells. J Immunol 2005;175:228-236. [PubMed: 15972653]

32. Fletcher JM, Ferrier PM, Gardner JO, Harkness L, Dhanjal S, Serhal P, Harper J, Delhanty J, Brownstein DG, Prasad YR, et al. Variations in humanized and defined culture conditions supporting derivation of new human embryonic stem cell lines. Cloning Stem Cells 2006;8:319-334. [PubMed: 17196096]

33. Ludwig TE, Levenstein ME, Jones JM, Berggren WT, Mitchen ER, Frane JL, Crandall LJ, Daigh CA, Conard KR, Piekarczyk MS, et al. Derivation of human embryonic stem cells in defined conditions. Nat Biotechnol 2006;24:185-187. [PubMed: 16388305]

34. Richards M, Fong CY, Chan WK, Wong PC, Bongso A. Human feeders support prolonged undifferentiated growth of human inner cell masses and embryonic stem cells. Nat Biotechnol 2002;20:933-936. [PubMed: 12161760]

35. Yao S, Chen S, Clark J, Hao E, Beattie GM, Hayek A, Ding S. Long-term self-renewal and directed differentiation of human embryonic stem cells in chemically defined conditions. Proc Natl Acad Sci U S A 2006;103:6907-6912. [PubMed: 16632596]

36. Heiskanen A, Satomaa T, Tiitinen S, Laitinen A, Mannelin S, Impola U, Mikkola M, Olsson C, MillerPodraza H, Blomqvist M, et al. N-glycolylneuraminic acid xenoantigen contamination of human embryonic and mesenchymal stem cells is substantially reversible. Stem Cells. 2006

37. Nasonkin IO, Koliatsos VE. Nonhuman sialic acid Neu5Gc is very low in human embryonic stem cell-derived neural precursors differentiated with B27/N2 and noggin: implications for transplantation. Exp Neurol 2006;201:525-529. [PubMed: 16806174]

38. Cerdan C, Bendall SC, Wang L, Stewart M, Werbowetski T, Bhatia M. Complement targeting of nonhuman sialic acid does not mediate cell death of human embryonic stem cells. Nat Med 2006;12:1113-1114. [PubMed: 17024197] author reply 1115

39. Ludwig TE, Bergendahl V, Levenstein ME, Yu J, Probasco MD, Thomson JA. Feeder-independent culture of human embryonic stem cells. Nat Methods 2006;3:637-646. [PubMed: 16862139]

40. Watkins WM. Blood-group substances. Science 1966;152:172-181. [PubMed: 12325343]

41. Bray J, Lemieux RU, McPherson TA. Use of a synthetic hapten in the demonstration of the ThomsenFriedenreich ( $\mathrm{T}$ ) antigen on neuraminidase-treated human red blood cells and lymphocytes. $\mathrm{J}$ Immunol 1981;126:1966-1969. [PubMed: 7217675]

42. Galili U, Rachmilewitz EA, Peleg A, Flechner I. A unique natural human IgG antibody with antialpha-galactosyl specificity. J Exp Med 1984;160:1519-1531. [PubMed: 6491603]

43. Galili U, Macher BA, Buehler J, Shohet SB. Human natural anti-alpha-galactosyl IgG. II. The specific recognition of alpha (1----3)-linked galactose residues. J Exp Med 1985;162:573-582. [PubMed: 2410529]

44*. Hewitt Z, Priddle H, Thomson A, Wojtacha D, McWhir J. Ablation of undifferentiated human embryonic stem cells: exploiting innate immunity against the Gal \{alpha\}1-3Gal\{beta\}14GlcNAc-R ( \{alpha\}-gal) epitope. Stem Cells. 2006The authors devise an interesting glycan-based strategy to genetically eliminate undifferentiated, potentially tumour-forming cells. HESC are transfected with the cDNA encoding the enzyme required to make the alpha-Gal epitope, to which high quantities of endogenous anti-alpha-Gal antibodies exist in human sera. On the one hand, it 
uses a natural approach to immunologically eliminate unwanted cells; while on the other hand, it highlights the antigenicity of glycans and their use to target specific cell populations

45. Benatuil L, Kaye J, Rich RF, Fishman JA, Green WR, Iacomini J. The influence of natural antibody specificity on antigen immunogenicity. Eur J Immunol 2005;35:2638-2647. [PubMed: 16082726]

46. Nash R, Neves L, Faast R, Pierce M, Dalton S. The lectin DBA recognizes glycan epitopes on the surface of murine embryonic stem cells: a new tool for characterizing pluripotent cells and early differentiation. Stem Cells. 2006

47. Venable A, Mitalipova M, Lyons I, Jones K, Shin S, Pierce M, Stice S. Lectin binding profiles of SSEA-4 enriched, pluripotent human embryonic stem cell surfaces. BMC Dev Biol 2005;5:15. [PubMed: 16033656]

48*. Wearne KA, Winter HC, O'Shea K, Goldstein IJ. Use of lectins for probing differentiated human embryonic stem cells for carbohydrates. Glycobiology 2006;16:981-990. [PubMed: 16809438]We selected this reference based on our belief that lectin profiling is one method which will lead to the identification of novel more efficient glycan markers for many stem cell states (undifferentiated, differentiating, partially differentiated and terminally differentiated). In this study, the authors used a panel of lectins and anti-carbohydrate antibodies to determine cell-surface glycan differences between human embryonic stem cells and day 12 embryoid bodies. Further studies of this type are needed to completely characterize the various stem cell glycomes 


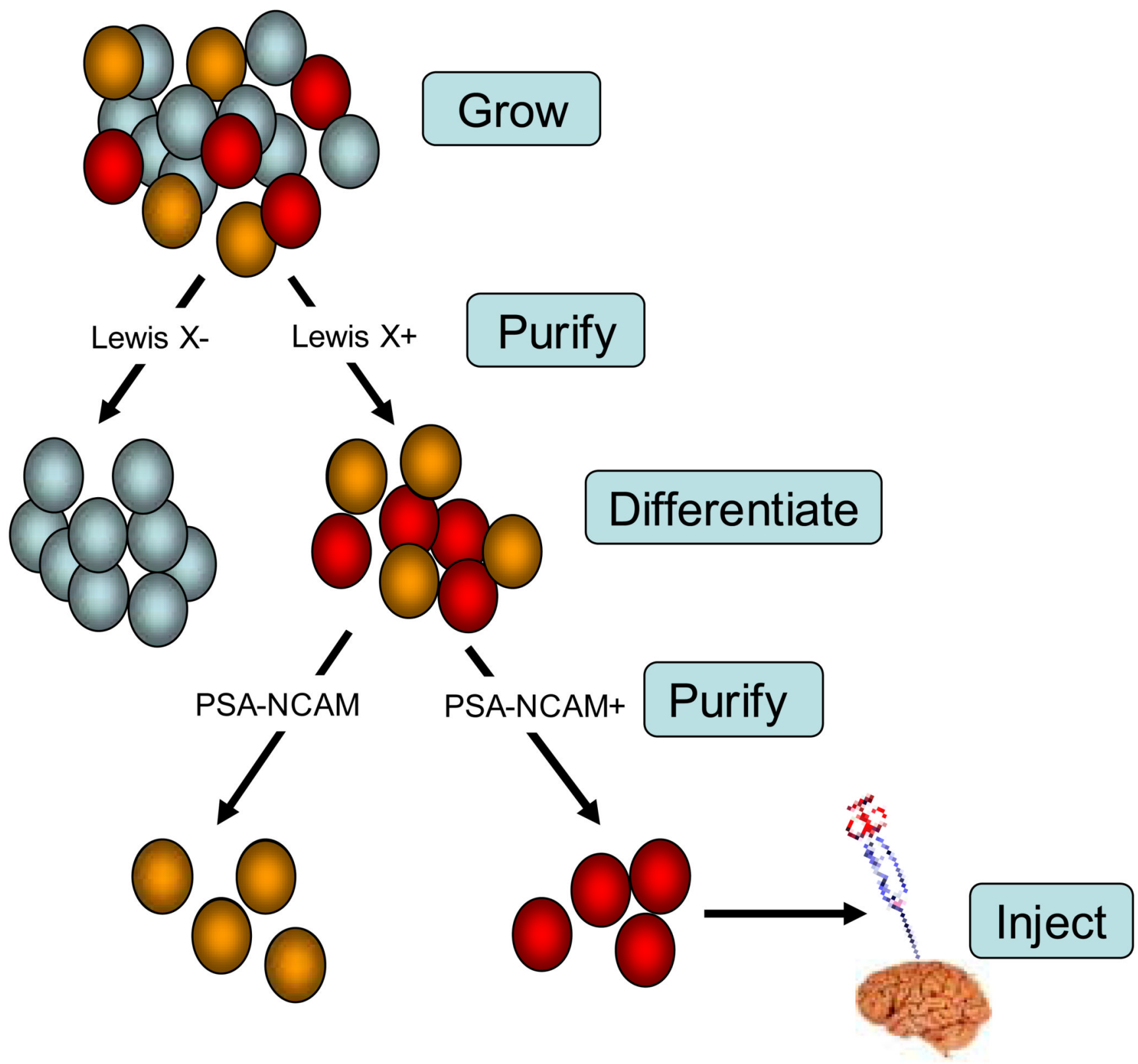

Figure 1. Hypothetical paradigm highlighting the use of glycans in stem cell preparation for therapeutic transplantation

FGF-2 driven proliferation of isolated neural stem cells is critically dependant on heparan sulfate proteoglycans (HSPG). Enrichment of this heterogeneous population can then be achieved by selecting Lewis X+ cells through flow activated cell sorting (FACS).

Differentiation involves modulation of signaling pathways such as Notch, Wnt and FGF-2, which are all regulated by various glycans. After induction of neuronal differentiation, another FACS-based purification step could select only cells expressing PSA-NCAM, a known marker of the neuronal lineage which is also involved in neurogenesis. Finally, the stem cell preparation could theoretically be injected locally in conjunction with various glycosidases (e.g. hyaluronidase), helping clear the way for proper integration into the matrix. 


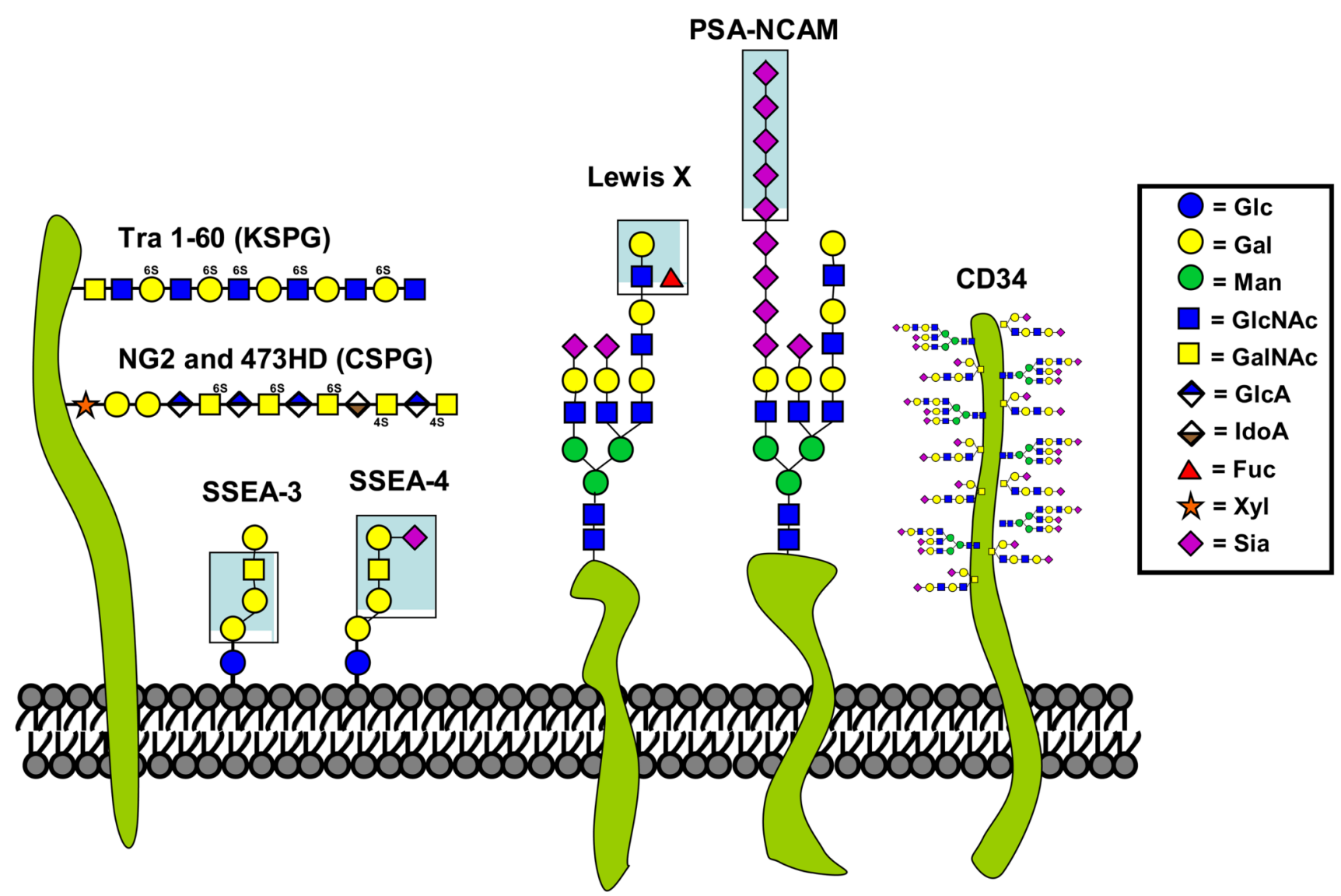

Figure 2. Schematic representation of some glycans markers used for the identification and purification of stem cells

Monosaccharides components of various glycans epitopes are presented in the boxed legend. Several pertinent glycan epitopes used for the identification and purification of stem cells are shown. They are TRA 1-60, NG2, 473HD, SSEA-3 and SSEA-4, Lewis X, PSA-NCAM, CD34, GalNAc. Whenever possible the exact glycan structure is highlighted by a blue box. 


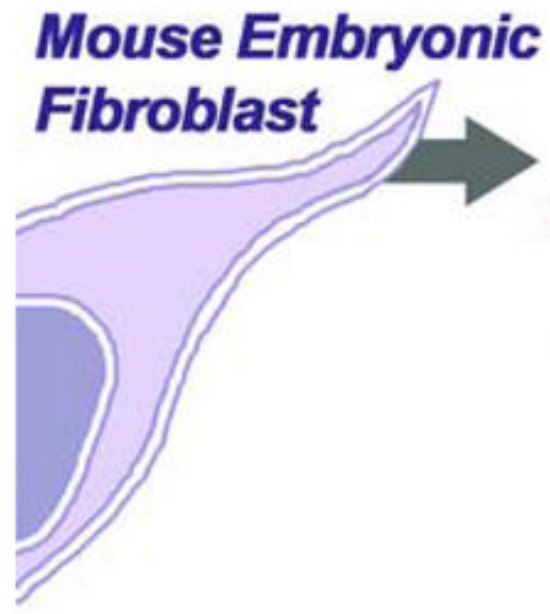

\section{NON-HUMAN GLYCOCONJUGATES}<smiles>C=CC=O</smiles>

\section{DIRECT INCORPORATION}

MACROPINOCYTOSIS<smiles>O=C1CCCC1=O</smiles><smiles>O[Ga]O[Mg]</smiles>

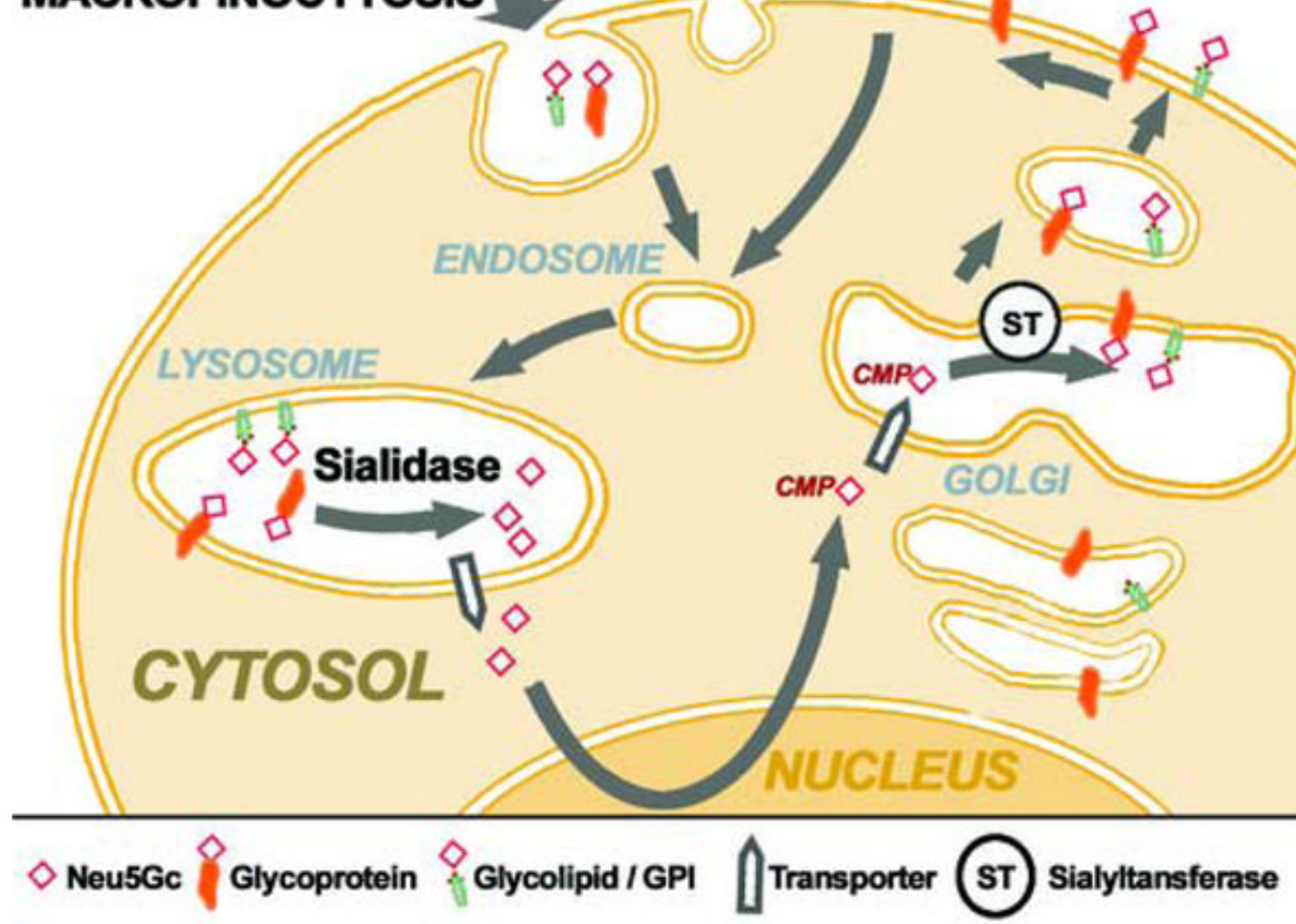

Figure 3. Schematic representation of mechanisms proposed for Neu5Gc contamination of human embryonic stem cells

Neu5Gc-containing glycoproteins and glycolipids/GPIs from culture medium and mouse embryonic fibroblasts become expressed on the surface of human embryonic stem cells. The first proposed mechanism involves direct incorporation of glycolipids/GPIs into the membrane. The second, more complex mechanism, involves macropinocytosis of Neu5Gc-

glycoconjugates. These contaminants are internalized to the lysosome where sialidases release free Neu5Gc and this is delivered to the cytoplasm through a lysosomal sialic acid transporter. Free Neu5Gc is then activated to CMP-Neu5Gc in the nucleus and sent back to the cytoplasm. Another sialic acid transporter then delivers CMP-Neu5Gc into the trans-Golgi where 
sialyltransferases (which do not discriminate much between CMP-Neu5Ac and CMP-Neu5Gc) add Neu5Gc from the latter to newly synthesized stem cell glycoconjugates. 